\title{
Description and Results: Antenna Measurement Facility Comparisons [Measurements Corner]
}

Alberica Saporetti, Maria; Foged, Lars; Sierra Castañer, Manuel; Pivnenko, Sergey; Cornelius, Rasmus; Heberling, Dirk

Published in:

I E E E Antennas and Propagation Magazine

Link to article, DOI:

10.1109/MAP.2017.2686097

Publication date:

2017

Document Version

Peer reviewed version

Link back to DTU Orbit

Citation (APA):

Alberica Saporetti, M., Foged, L., Sierra Castañer, M., Pivnenko, S., Cornelius, R., \& Heberling, D. (2017).

Description and Results: Antenna Measurement Facility Comparisons [Measurements Corner]. I E E E Antennas and Propagation Magazine, 59(3), 108-116. https://doi.org/10.1109/MAP.2017.2686097

\section{General rights}

Copyright and moral rights for the publications made accessible in the public portal are retained by the authors and/or other copyright owners and it is a condition of accessing publications that users recognise and abide by the legal requirements associated with these rights.

- Users may download and print one copy of any publication from the public portal for the purpose of private study or research.

- You may not further distribute the material or use it for any profit-making activity or commercial gain

- You may freely distribute the URL identifying the publication in the public portal 


\title{
Description and Results of Antenna Measurement Facility Comparisons in EurAAP
}

\author{
M. A. Saporetti ${ }^{1}$, L. J. Foged ${ }^{1}$, M. Sierra-Castaner ${ }^{2}$, S. Pivnenko ${ }^{3}$, R. Cornelius ${ }^{4}$, D. Herberling ${ }^{4}$ \\ ${ }^{1}$ Microwave Vision Italy (MVI), Via dei Castelli Romani 59, 00040 Pomezia, Italy \\ Email: maria.saporetti@microwavevision.com, lars.foged@microwavevision.com \\ ${ }^{2}$ Grupo de Radiación. ETSI Telecomunicación. Universidad Politécnica de Madrid, Spain \\ E-mail: mscastaner@gr.ssr.upm.es \\ ${ }^{3}$ Antenna Systems Solutions (ASYSOL), Calle Albert Einstein 14, 39011 Santander, Spain \\ spivnenko@asysol.com \\ ${ }^{4}$ Institute of High Frequency Technology, RWTH Aachen, Germany \\ cornelius@ihf.rwth-aachen.de
}

\begin{abstract}
In recent years, formalized facility comparison activities have become important for documentation and validation of laboratory proficiency and competence. They have become mandatory to achieve accreditation like ISO 17025 or similar [1]. Different inter-comparison campaigns have been conducted on antenna measurements in the frame of various European activities. The activities were initiated in 2004 with the $6^{\text {th }}$ EU framework network "Antenna Centre of Excellence" (ACE) [2]. The work continued under the management of EurAAP (European Association on Antennas and Propagation) supported by the European Cooperation in Science and Technology (COST) in the programs ASSIST IC0603 and VISTA IC1102 including still on-going campaigns [3-5]. Results of these activities have led to improvement in antenna measurement procedures / protocols in facilities and standards [6,7]. Due to the direct benefits to the participants, the activities have been very successful and partial outcomes have been published in IEEE referenced papers during the years [8-18].

The analysis and data elaboration has fostered fruitful discussions and led to modernization and harmonization of comparison techniques such as reference pattern, including estimates of the uncertainty and equivalent noise level. The very large set of measured information, collected in the campaigns, constitutes a valuable database of information that could potentially be available to the antenna measurement community for exploitation in further studies and analysis. As a further benefit, the campaigns have initiated a dialogue among different laboratories throughout Europe and USA.

This paper presents the background, history and status of the facility comparison activities within EurAAP. The management and data collecting organization is discussed in detail and is crucial for the successful outcome. The data elaborations strategies have recently been revised and the results are summarized in this paper. Four of the recent activities are presented of which some of them are still on-going to illustrate typical activities.
\end{abstract}

Keywords: antenna measurements, radiation patterns, inter-comparison campaigns.

\section{Introduction}

The measurement of antenna gain / directivity in a certain direction or any other antenna performance parameter is considered to be incomplete without knowledge of the measurement accuracy. An important part of the facility documentation is, therefore, devoted to provide and justify proper measurement error estimates $[1,6,7]$.

Independently of the technology and measurement approach, most measurement ranges have internal procedures, uncertainty budgets, quality policy, reference antennas for gain and a certain measurement experience. Some facilities even have certification as a reference facility like ISO 17025 [1]. Such accreditation is a formal 
recognition of that competence. In any case, the measurement uncertainty or error estimate for a given antenna, in a given measurement range, remains an approximation until this estimate has been successfully validated against other measurements.

For this reason, all facilities, with and without formal certification, need to regularly pursue activities to properly validate their measurement procedures. The main goal of the facility comparison activities is to provide a formal opportunity for the participants to validate and document their achieved measurement accuracy and procedures by comparison with other facilities.

These campaigns have shown that comparative measurements based on high accuracy reference antennas and involving different antenna measurement systems are important instruments in the evaluation, benchmarking and calibration of the measurement facilities. They also have proven to be important instruments to investigate and evaluate possible improvements in measurement setups and procedures.

Further activities have concerned the improvement of standard procedures / protocols and tools for verification like the facility comparison campaigns, fostering a fruitful discussion on the modernization and harmonization of the techniques to determine the reference pattern, the noise level and the error budget.

In this paper, we will give an overview on:

- History of Facility Comparison Campaigns in EurAAP and on-going campaigns;

- implementation and procedures;

- measurements comparison;

- preliminary results of the BTS campaign.

\section{Brief History of Facility Comparison Campaigns in EurAAP}

Facility comparison campaigns are an important ongoing activity in the frame of the EurAAP working group on antennas measurements [3]. This work comes from the experience acquired during the $6^{\text {th }}$ EU Framework network "Antenna Centre of Excellence (ACE)" [2] as reported in $[8,15]$. The antenna measurement activity of the Antenna Centre of Excellence of the $6^{\text {th }}$ Frame Program of the EU, in the period of 2004-2007, began to define some reference antennas: A high directive reflector antenna, DTU-ESA $12 \mathrm{GHz}$ VAST12 [19] and two Dual-Ridge Horns, MVI / SATIMO SH800 [20] in L, S, C bands and MVI / SATIMO SH2000 in $\mathrm{Ku}$ and $\mathrm{Ka}$ bands.

Successively, the different activities related to this topic have been developed in the frame of the COST ASSIST (IC0603) [4] and COST VISTA (IC1102) [5], and were then included in the EurAAP measurement working group where a specific on-going task for Antenna Measurement Intercomparison has been approved. To provide a comprehensive set of highly stable reference antennas in terms of type and bands (from $\mathrm{L}$ to $\mathrm{Ka}$ ), the following campaigns (some are still on-going) were selected:

1) L-band Base-Station antenna with directive elevation beam and wide azimuth beam, MVI / SATIMO BTS1940;

2) $\mathrm{X} / \mathrm{Ku} / \mathrm{Ka}$-band high gain reflector antenna, MVI / SATIMO SR40-A fed by SH4000 Dual Ridge Horn;

3) L/C-band medium gain ridge horn, MVI / SATIMO SH800 with absorbers plate;

4) CTIA MIMO LTE antennas (in collaboration with the EurAAP Small Antennas Working Group).

\subsection{MVI / SATIMO BTS1940 Campaign}

The antenna is a linear array with dual slant $\pm 45^{\circ}$ or $\mathrm{H} / \mathrm{V}$ polarized working in GSM1800 and UMTS bands (1710 to $2170 \mathrm{MHz}$ ) as shown in Fig. 1. The linear array antenna is specifically designed to achieve excellent crosspolar discrimination and to maintain a well-defined radiation pattern in the direction of the boresight axis throughout the operational bandwidth. The BTS1940 family of reference antennas is equipped with high precision female N-type connectors for superior repeatability and durability. The nominal impedance is $50 \mathrm{Ohm}$ with return loss values better than $15 \mathrm{~dB}$.

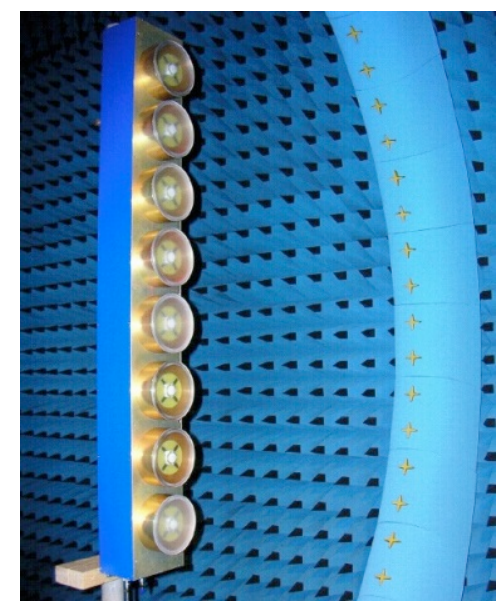

Fig. 1: MVI/SATIMO BTS 1940-01 high accuracy reference antenna.

The BTS campaign started in 2009 and will end in 2016. The BTS has been measured in all the facilities shown in Fig. 2.

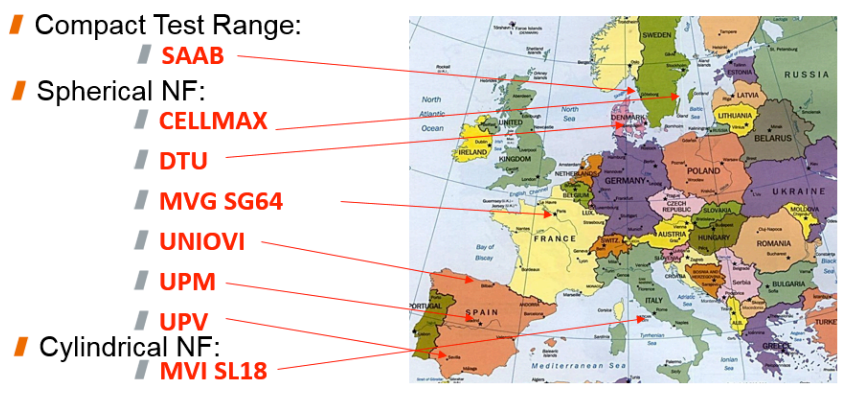

Fig. 2: European location of the facilities involved in the BTS campaign. 


\subsection{Reflector SR40-A fed by SH4000 Dual Ridge Horn Campaign}

In order to cover also higher frequencies and higher directivity antennas, the MVI/SATIMO SR40-A fed by SH4000 Dual-Ridge Horn reference antenna (Fig. 3) has been selected. The SR40-A is a high precision offset parabolic reflector for wideband high gain antenna measurements. The circular interface allows the user to center the antenna with very high accuracy. The alignment accuracy is estimated in $\pm 0.01^{\circ}$ on azimuth.

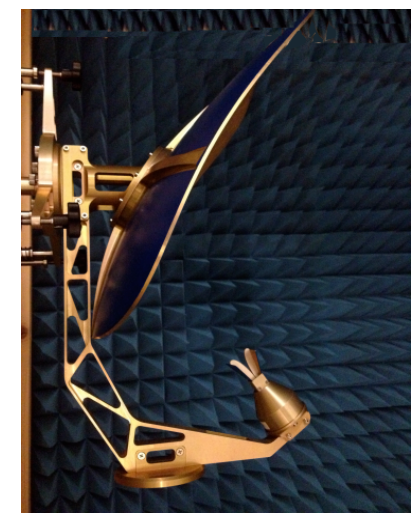

Fig. 3: Reflector SR 40-A fed by SH4000 Dual Ridge Horn.

The campaign started in 2013 and measurements have been concluded in 2016. Data post-processing is on-going. The facilities who took part to the Reflector SR40$\mathrm{A}+\mathrm{SH} 4000$ are shown in Fig. 4.

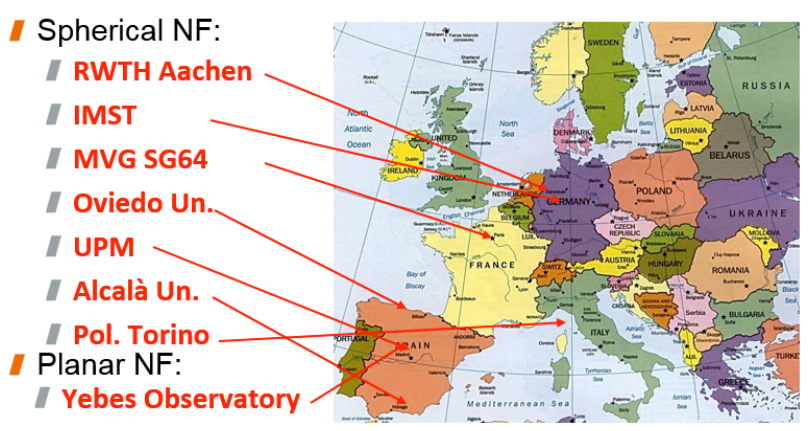

Fig. 4: Involved facilities in the reflector SR40-A+SH4000 campaign.

\subsection{MVI / SATIMO SH800 with Absorbers Plate Campaign}

MVI/SATIMO SH800 is a Dual-Ridge Horn which combines stable gain performance and low VSWR with wideband frequency operation. The horn is single linearly polarized with excellent cross-polar discrimination. The unique horn design suppresses any possible excitation of higher order modes in the aperture and maintains a welldefined smooth radiation pattern in the direction of the boresight axis throughout the operational bandwidth. In this campaign, the antenna has been modified in order to have a more stable setup. In particular, an absorber plate has been added behind the antenna to eliminate the sensitivity to the measurement setup, as shown in Fig. 5.

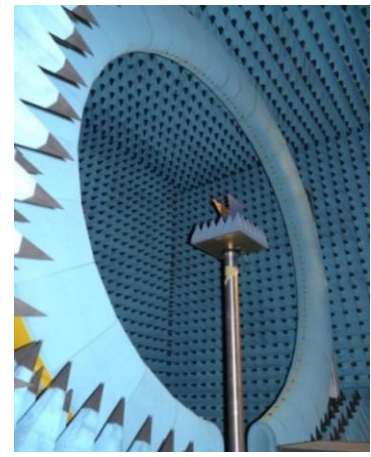

Fig. 5: MVI/SATIMO SH800 with absorbers plate.

The campaign started in 2013 and at the end of 2015 all the European participants, shown in Fig. 6, had measured the antenna. In 2016 the antenna has been sent to USA facilities.

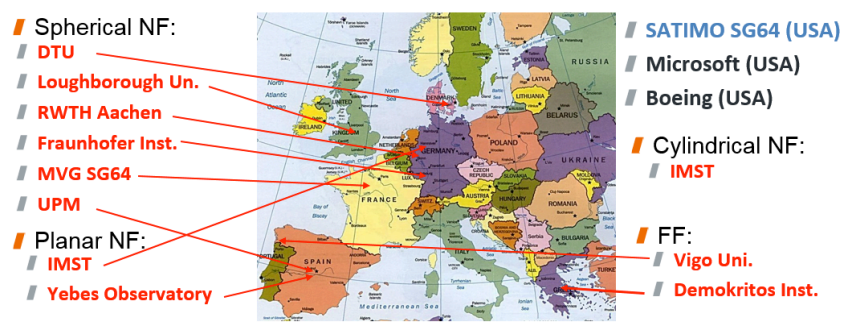

Fig.6: European location of the facilities involved in the SH800+absorbers plate campaign.

\subsection{LTE CTIA MIMO Antennas Campaign}

In order to cover also small antenna measurements, a campaign involving CTIA 2x2 MIMO reference antennas (Fig. 7) has been defined.

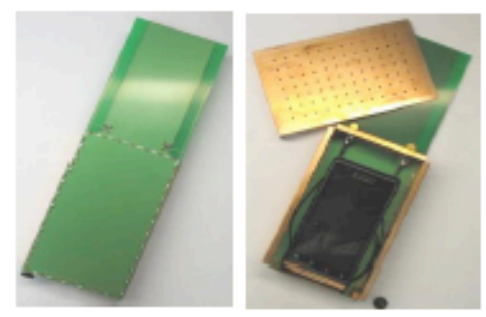

Fig. 7: MIMO reference antenna for LTE.

The set of MIMO reference antennas includes the following:

LTE Band 2 [1930-1990] MHz:

- Good,

- Nominal,

LTE Band 7 [2620-2690] MHz:

- Good,

- Nominal,

LTE Band 13 [746-756] MHz:

- Good,

- Bad,

- Nominal, 
where "Good" stands for a correlation coefficient $<0.1$; "Bad" for a correlation coefficient $>0.9$; "Nominal" for a correlation coefficient $=0.5$.

This campaign started in mid-2015 and it is managed in collaboration of the EurAAP WG about "Small Antennas" and "Measurements". So far only IMST and MVG have measured the antenna.

\section{Management of Facility Comparison Campaigns in EurAAP}

A campaign leader or institution conducts the facility comparison campaigns. The management of these intercomparison activities has been complex and has required corresponding regulation. Each participant has to sign a "Participation agreement" document that contains the terms and the conditions of the participation. For some more delicate reference antennas a "Packaging/Handling Instruction Document" is provided. The selected antenna is first measured in the facility of the leader and is measured again after the end of the campaign to ensure that nothing has occurred to the antenna during the campaign. The antenna is shipped directly between the participants with a transportation insurance, which must be covered by the transportation company. In the last years, the EurAAP WG Activity Budget has covered the transportation costs and insurance for shipment. In addition, to ensure that no physical harms has occurred to the antenna during the shipping, each facility is asked for photographic documentation of the antenna and shipping box at the arrival in the institution.

As different laboratories are interested in measuring different antenna performance figures, in order to meet everyone's need, the "typical" antenna performance figures common to most measurement situations are required:

1. Peak gain (IEEE definition) at discrete frequencies. Some provide frequency sweep.

2. Directivity/Gain patterns in appropriate steps. Ludwig III Co / Cx.

3. Data format EDX or Excel file with a predefined format.

4. S-Parameters.

5. Description of measurement facility (photo).

6. Mechanical and electrical setup description (photo).

7. Measurement procedure.

8. Mechanical / electrical alignment, AUT alignment

9. Uncertainty budget (not for all the facilities, as will be explained later).

The comparison leader collects the measured and processed data for comparison processing, following a strict procedure. Data of each participant is "incognito" to other participants before officially released. Each participant can investigate his results against a set of "reference" data provided by the comparison manager based on other measurements. If there are no evident errors and the participant agrees, the measured data is released and accepted in the campaign. The participant may also choose to investigate his measurement further or perform a new measurement to correct for errors. Only after each participant accepts his results, the data are officially released and accepted in the campaign.

Since 2005, completed facility campaigns have been published in several IEEE referenced papers throughout the years and presented at COST meetings.

\section{Measurements Comparison}

The reliable approach to determine

- the reference pattern and its uncertainty, from several independent measurements and

- the correlation between the reference pattern and each measurement expressed through the equivalent noise level

is of crucial importance to evaluate the results of an intercomparison campaign.

Many methods exist and have been compared in literature, especially by the "National Institute of Standards and Technology", to analyse measurements data sets with certain values of uncertainties [21], resulting from national measurement laboratories of a Ku-band Standard Gain Horn [22-25].

Research activities whose reliability has been verified with the available large amount of measurement data have been carried on among EurAAP WG5 components. This study has aimed at defining the best way to:

- Determine the reference pattern and its uncertainty through a proper combination of measurements and weights, involving the uncertainty budgets of the results;

- Evaluate the consistency of the declared uncertainty budgets;

- Express the difference between two radiation patterns to compute the equivalent noise level between the reference pattern and each measured pattern.

In the following sections, the achieved results and the agreed methodology chosen to evaluate the measurement data coming from EurAAP inter-comparison campaigns are shown.

\subsection{Reference Pattern}

Defining a common best value among different measures implies the computation of an average. Averaged data can be obtained through a simple mean or a weighted mean.

The measurement results have different uncertainties, being performed in different facilities, which are characterized by an estimated uncertainty. Therefore, it is more correct to take them into account using a weighted mean. A simple mean does not appear to be the best solution because it would give the same probability to all samples and would be the best choice only if one was to 
perform a measurement in a randomly chosen measurement chamber each time.

The best way to compute the reference pattern is to use a weighted linear mean:

$$
\mu_{\text {Lin }}=\frac{\sum_{i=1}^{n} w_{i} x_{i_{\text {Lin }}}}{\sum_{i=1}^{n} w_{i \text { Lin }}}
$$

where

$n=$ total number of participants (and of measurements),

$i=$ measurement of the ith participant to the campaign,

$x_{i L i n}=$ linear measurement.

The value for the weight $w_{i}$ associated to the $i^{\text {th }}$ measurement is given by:

$$
w_{i_{\text {Lin }}}=\frac{1}{\sigma_{i \operatorname{Lin}}^{2}}
$$

$\sigma_{\text {Lin }}$ is the linear uncertainty computed starting from $\sigma_{d B}$ that is the uncertainty, related to the measurement, declared by each facility:

$$
\sigma_{\text {Lin }}=\left(10^{\left(\sigma_{d B} / 20\right)}-1\right) x_{L i n} .
$$

The uncertainty related to the weighted mean (1) is given by:

$$
\sigma_{\mu L i n}=\sqrt{\frac{1}{\sum_{i=1}^{n} \frac{1}{\sigma_{i L i n}^{2}}}}
$$

\subsection{Uncertainty Budget Consistency Check}

The weights (Eq. 2) for the computation of the reference pattern depend on the uncertainty budget. As already mentioned, the facilities are required to provide a standard deviation $\sigma$ which is useful to quantify the range in which the measurements errors are distributed. It expresses the $68.3 \%$ confidence that the measurements error is within this level $(99.7 \%$ is $3 \sigma)$ assuming a normal distribution. The uncertainty is calculated by each facility with its own procedures. The selected methods to check the consistency of the declared uncertainties are:

- Standard Deviation,

- $\quad$ Birge ratio [26],

- $\quad$ E and Z scores.

A commonly used strategy in facility comparisons is to exclude one or more results that are not conformal to the general consensus. The purpose of this approach is to avoid having a bad result "pollute" the campaign. However, since these campaigns have statistically few participants, such procedure is an expensive way to assure convergence. A further drawback of this approach is that the excluded participants are put in a delicate situation. Wrong measurement results are often due to human or component failure. The purpose of the facility comparison is not to investigate such errors but to validate and confirm uncertainty budgets based on correctly executed procedures and equipment.

\subsection{Equivalent Noise Level Determination}

The correlation between each measurement and the reference pattern can be expressed though a single value. All the deviations with respect to the reference pattern are converted into an equivalent "noise" level. The expression for the equivalent noise level, evaluated on a limited $\left( \pm 45^{\circ}\right.$ or $\pm 60^{\circ}$ ) theta cone when directivity data are available is the following:

$$
E q N=\left[\sqrt{\frac{1}{n-1} \sum_{i=\theta_{1}}^{n}\left(\frac{D i r_{i_{-} c o, c x}-\text { Dir }_{i_{-} r e f \_c o, c x}}{D i r_{c o, r e f, b o r e s i g h t}}\right)^{2}}\right]
$$

where $n$ is the total number of points comprised in the theta cone ( 91 if the cone is $\pm 45^{\circ}, 121$ if the cone is $\pm 60^{\circ}$ ), $i$ is the point of the theta cone: $\theta_{1}=-45^{\circ}$ or $-60^{\circ}$ and $\theta_{n}=45^{\circ}$ or $60^{\circ}, D i r_{i} c 0, c x=$ Directivity $(\mathrm{Co}$ or $\mathrm{Cx})$ of the measured

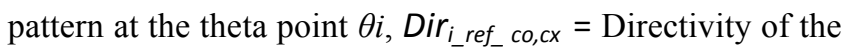
reference pattern (Co or $\mathrm{Cx}$ ) at the point $\theta i$, Dir ${ }_{\text {co,ref,boresight }}$ $=$ Directivity of the co-polar component of the measured pattern in boresight.

The formula for the Equivalent Noise (Eq. 5) corresponds to the computation of the Root Mean Square Error of the expression inside the round brackets.

If only the gain is available, then, in order to have a value that gives information on the pattern envelope error without being affected by the gain error, measured directivity data must be replaced by GainOffset which is obtained subtracting a constant offset (in $\mathrm{dB}$ ) all over the measured gain pattern

$$
\text { GainOffset }_{d B}=\text { Gain }_{d B}-\text { Offset }_{d B}
$$

and the offset is given by:

$$
\text { Offset }_{d B}=\text { Gain }_{d B, c o \_b o r e s i g h t}-\text { Gain }_{d B, c o, \text { ref_boresight }} \text {. (7) }
$$

The offset application corresponds to a normalization w.r.t. to the boresight reference. Therefore, the formula to be used is:

$$
E q N=\left[R M S E\left(\frac{\text { GainOffset }_{c o, x p}-\text { Gain }_{r e f \_c o, x p}}{\text { Gain }_{c o, r e f \_b o r e s i g h t}}\right)\right]
$$




\section{MVI / SATIMO BTS1940-01 Campaign Results}

\subsection{Test Plan}

The test plan and type of measurements are reported in Table 1 .

\begin{tabular}{|c|l|l|}
\hline \multirow{2}{*}{$\begin{array}{c}\text { Full } \\
\text { 3D } \\
\text { Gain }\end{array}$} & Frequency Range & $1500-2400 \mathrm{MHz}-5 \mathrm{MHz}$ step \\
\cline { 2 - 3 } $\begin{array}{c}\text { Measu } \\
\text { rement }\end{array}$ & Phi & From $0^{\circ}$ to $135^{\circ}\left(45^{\circ}\right.$ step $)$ \\
\cline { 2 - 3 } & Theta & From $-180^{\circ}$ to $180^{\circ}\left(1^{\circ}\right.$ step $)$ \\
\hline
\end{tabular}

Tab. 1: Required measurements for MVI / SATIMO BTS1940-01

\subsection{Results} campaign

The results that will be shown hereafter are referred to the following facilities: DTU, UPM, SAAB, MVG SG64, MVI-SL, CELLMAX.

The weighted reference pattern has been computed according to the facilities and uncertainties reported in Table 2 .

\begin{tabular}{|l|c|}
\hline \multicolumn{1}{|c|}{ Facility } & Uncertainty [dB] \\
\hline DTU & \pm 0.240 \\
\hline UPM & \pm 0.313 \\
\hline SAAB & \pm 0.525 \\
\hline MVG-SG & \pm 0.500 \\
\hline
\end{tabular}

Tab. 2: Facilities and uncertainties for the reference pattern computation

\subsubsection{Radiation Patterns}

Measured co-polar and cross-polar pattern at $\mathrm{phi}=0^{\circ}$ and $90^{\circ}$ at 1.71 and $1.92 \mathrm{GHz}$ are compared with the weighted reference pattern (computed with Eq. 1) from Fig. 8 to Fig. 11 . In the cut phi $=90^{\circ}$ the angular range has been reduced to $-60^{\circ}-120^{\circ}$ because of some disagreements among the patterns caused by positioner effects of the different range types.

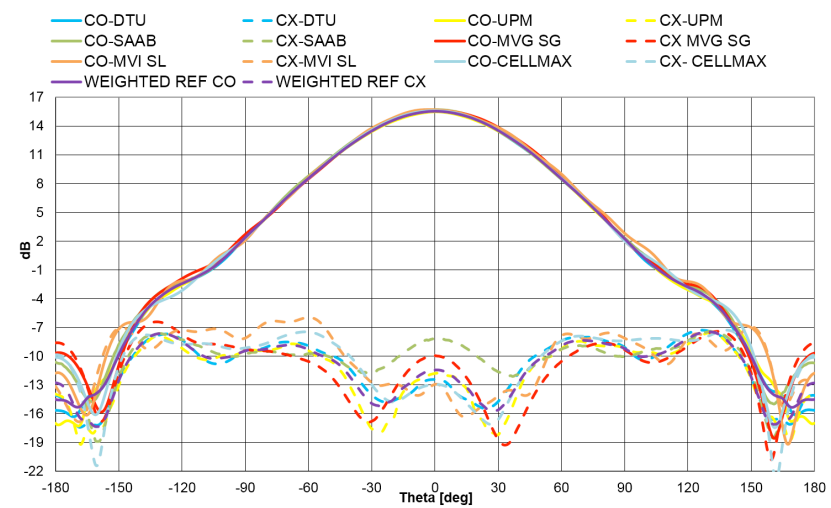

Fig. 8: Gain radiation pattern - azimuth cut, phi=0 $@ 1.71 \mathrm{GHz}$. Weighted reference, DTU, UPM, SAAB, MVG-SG, MVI-SL,CELLMAX.

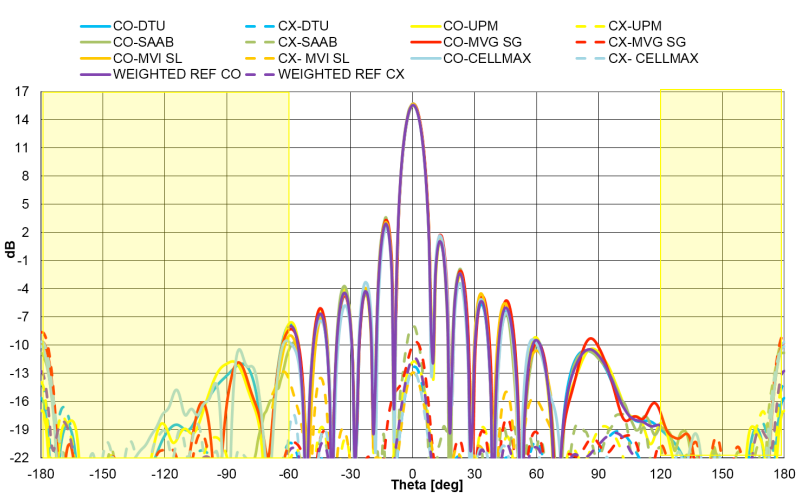

Fig. 9: Gain radiation pattern -elevation cut, phi=90@1.71 GHz. Weighted reference, DTU, UPM, SAAB, MVG-SG, MVI-SL, CELLMAX.

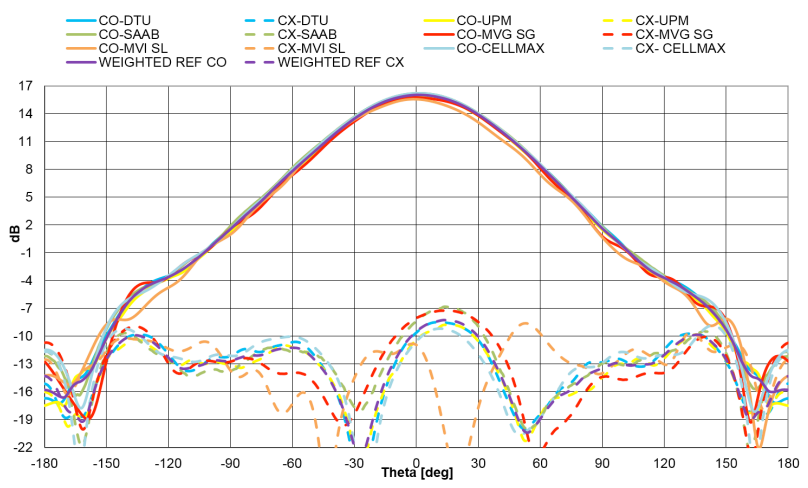

Fig. 10: Gain radiation - pattern azimuth cut, phi=0@ $1.92 \mathrm{GHz}$. Weighted reference, DTU, UPM, SAAB, MVG-SG, MVI-SL, CELLMAX.

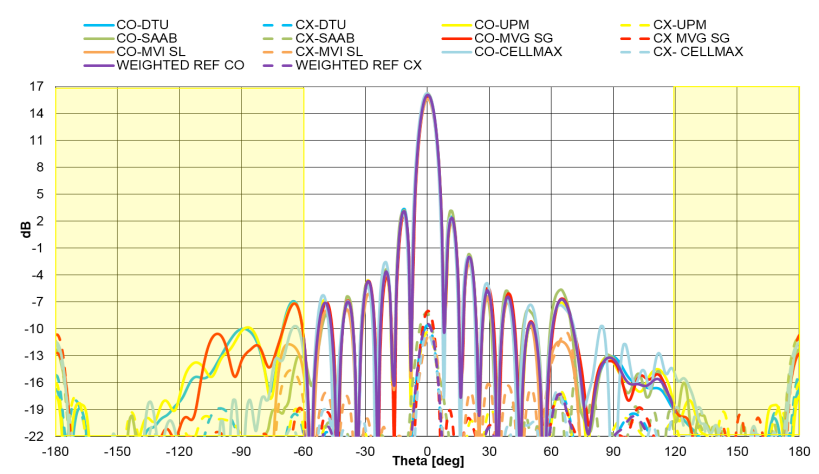

Fig. 11: Gain radiation pattern - elevation cut, phi=90@1.92 GHz. Weighted reference, DTU, UPM, SAAB, MVG-SG, MVI-SL, CELLMAX.

\subsubsection{Equivalent Noise Level}

The equivalent noise level computed with offset gain patterns in a $\pm 45^{\circ}$ theta cone is reported in Fig. 12 and Fig.13@1.71, 1.92, 2.17 and 2.20 GHz. The noise level has been computed in the azimuth and in the elevation planes for the co-polar component. The values of the peak gain are reported in Table 3 . The equivalent error level as a function of theta at $1.71 \mathrm{GHz}$ is shown for the co-polar components in the azimuth and elevation planes for all facilities in Fig. 14 and Fig. 15. 


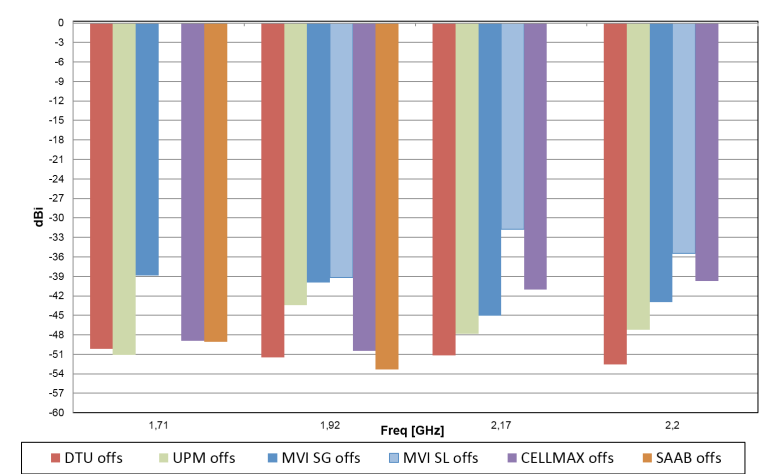

Fig. 12: Equivalent noise level in the azimuth plane, for the co-polar component for DTU, UPM, MVG SG, MVI SL and SAAB.

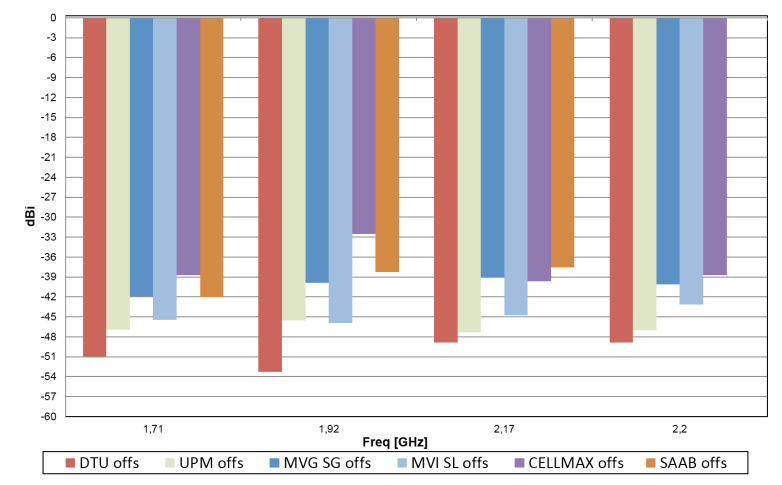

Fig. 13: Equivalent noise level in the elevation plane, for the co-polar component for DTU, UPM, MVG SG, MVI SL and SAAB.

\begin{tabular}{|c|c|c|c|c|c|c|c|}
\hline \multirow{2}{*}{$\begin{array}{c}\text { Freq } \\
\text { [GHz] }\end{array}$} & \multicolumn{7}{|c|}{ Peak Gain } \\
\cline { 2 - 8 } & REF & DTU & UPM & $\begin{array}{c}\text { MVG } \\
\text { SG64 }\end{array}$ & $\begin{array}{c}\text { MVI } \\
\text { SL }\end{array}$ & SAAB & $\begin{array}{c}\text { CELL } \\
\text { MAX }\end{array}$ \\
\hline 1.71 & 15.54 & 15.51 & 15.48 & 15.64 & 15.69 & 15.72 & 15.57 \\
\hline 1.92 & 16.07 & 16.15 & 16.00 & 15.75 & 15.60 & 16.24 & 16.23 \\
\hline 2.17 & 16.60 & 16.82 & 16.39 & 16.43 & 16.03 & 16.41 & 16.54 \\
\hline 2.20 & 16.58 & 16.73 & 16.43 & 16.37 & 15.95 & - & 16.50 \\
\hline
\end{tabular}

Tab. 3: Peak gain and offset corrections for: reference, DTU, UPM, MVG SG64, MVI SL, SAAB, CELLMAX @1.71, 1.92, 2.17, 2.2 GHz.

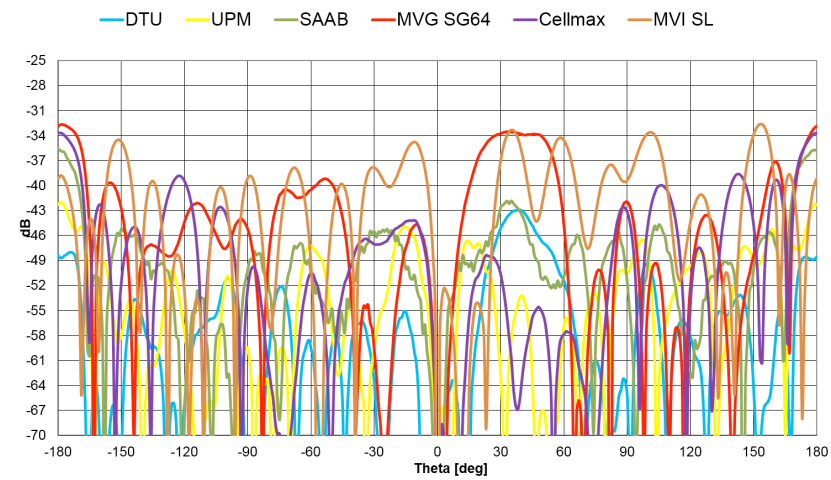

Fig. 14: Equivalent noise level in the azimuth plane w.r.t. theta for the copolar component for DTU, UPM, MVG SG64, MVI SL, SAAB, CELLMAX@1.71 GHz.

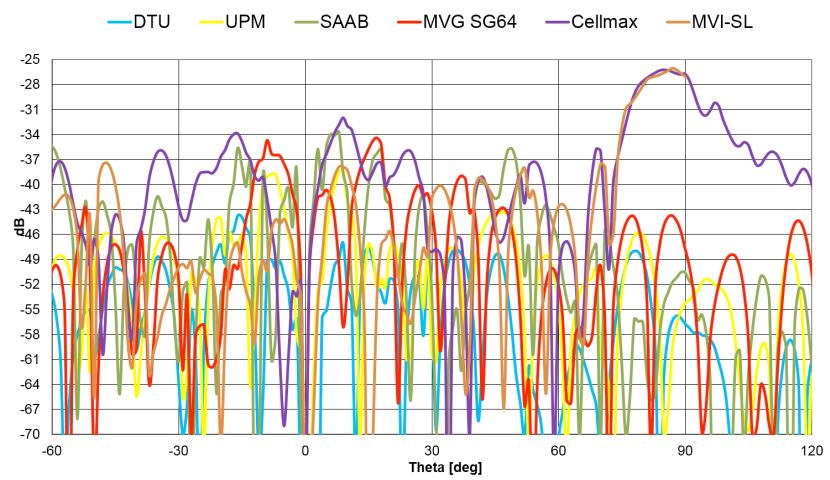

Fig. 15: Equivalent noise level in the azimuth plane w.r.t. theta for the copolar component for DTU, UPM, MVG SG64, MVI SL, SAAB, CELLMAX@1.71 GHz.

\section{Conclusions}

The status of facility comparison actives during the last 10 years supported by EurAAP has been presented. Due to the nature of such campaigns, the duration is often measured in years and constitutes serious commitment (time) and investment (money) by the participants and campaign leader. A campaign cannot be successful unless the participants have full confidence in the organization of the campaign.

To be successful, the campaign must have well-defined and documented procedures for all aspects of the campaign. It is therefore highly important that the purpose of the campaign is communicated and well-documented. In particular a "Participation agreement" document, containing the terms and the conditions of the participation, has to be signed. For some more delicate reference antennas, a "Packaging / Handling Instruction Document" is provided.

However, an important lesson that we have learned is that the campaign cannot fully rely only on written documentation so the task of the campaign leader must include a personal contact support function.

The campaigns have shown that comparative measurements based on high accuracy reference antennas and involving different antenna measurement systems are important instruments in the evaluation, benchmarking and calibration of measurement facilities. EurAAP will continue working on these campaigns. The very large amount of measurement information collected in the frame of these campaigns constitutes a valuable database that could be potentially made available to the antenna measurement community to be exploited for further studies and analysis.

\section{Acknowledgment}

The authors want to thank the COST-VISTA and EurAAP for the support to this paper. 


\section{References}

1. www.isoiec17025.com

2. http://www.ist-ace.org/

3. EurAAP, "European Association on Antennas and Propagation", www.euraap.org

4. COST ASSIST IC0603,"Antenna Systems and Sensors for Information Society Technologies", www.costic0603.org

5. COST VISTA IC1102, "Action on Versatile, Integrated and Signal-aware Technologies for Antennas", www.cost-vista.eu

6. ANSI/IEEE Standard 149-1979, "Test Procedures for Antennas".

7. IEEE Standard 1720-2012, "Reccomended practices for near-field antenna measuremenst".

8. L. J. Foged, P. Garreau, O. Breinbjerg, S. Pivnenko, M. Castañer, J. Zackrisson "Facility comparison and evaluation using dual ridge horn," AMTA 2005, Newport, USA.

9. L. J. Foged, P. O Iversen, L. Duchesne, O. Breinbjerg, S. Pivnenko, "Comparative Measurement of standard gain horns," 28th ESA antenna workshop on Space Antenna Systems and Technologies, 31 May - 3 June 2005, Noordwijk, The Netherlands.

10. L. J. Foged, O. Breinbjerg, S. Pivnenko, G. Di Massa, C. Sabatier, "Antenna measurement facility comparison within the European Antenna Centre of Excellence," European Microwave Conference, 4-6 Oct. 2005.

11. A. Giacomini, B. Bencivenga, L. Duchesne, L. J. Foged, "Determination of high accuracy performance data for dipole reference antennas," Proc. of the First Antenna MeasurementsTechniques Association Europe (AMTA Europe) Symposium, Munich, May 2006".

12. L J. Foged, B. Bencivenga, L. Durand, O. Breinbjerg, S. Pivnenko, C. Sabatier, H. Ericsson, B Svensson, A. Alexandridis, S. Burgos, M. Sierra-Castañer, J. Zackrisson, M. Boettcher "Error calculation techniques and their application to the Antenna Measurement Facility Comparison within the European Antenna Centre of Excellence," 2nd European Conference on Antennas and Propagation, EuCAP, $11-$ 16 Nov. 2007 Edinburgh, UK.

13. L. J. Foged, B. Bencivenga, O. Breinbjerg, S. Pivnenko, M. Sierra-Castañer, "Measurement facility comparisons within the European antenna centre of excellence," ISAP2008, International symposium on Antennas and propagation. 27-30 October 2008. Taipei, Taiwan.

14. S. Pivnenko, O. Breinbjerg, S. Burgos, M. SierraCastañer, H. Eriksson, "Dedicated Measurement Campaign for Definition of Accurate Reference Pattern of the VAST12 Antenna," 2008 AMTA Symposium.

15. L. J. Foged, B. Bencivenga, L. Scialacqua, S. Pivnenko, O. Breinbjerg, M. Sierra-Castañer, P. C. Almena, E. Séguenot, C. Sabatier, M. Böttcher, E. Arnaud, T. Monediere, H. Garcia, D. Allenic, G. Hampton, A. Daya, "Facility comparison and evaluation using dual ridge horns," 3th European Conference on Antennas and Propagation, EuCAP, Berlin, March 2009.

16. S. Pivnenko, J.E. Pallesen, O. Breinbjerg, M. SierraCastañer, P. Caballero, C. Martínez, J.L. Besada, J. Romeu, S. Blanch, J.M. González-Arbesu, C. Sabatier, A. Calderone, G. Portier, H. Eriksson, J. Zackrisson. "Comparison of Antenna Measurement Facilities With the DTU-ESA $12 \mathrm{GHz}$ Validation Standard Antenna Within the EU Antenna Centre of
Excellence," IEEE Transactions on Antennas and Propagation, July 2009. Vol. 57. N. 7. pp. 1863-1878.

17. L. J. Foged, M. Sierra Castañer, L. Scialacqua "Facility Comparison Campaigns within EurAAP," 5th European Conference on Antennas and Propagation, EuCAP, Rome, April 2011.

18. L. Scialacqua, F. Mioc, J. Zhang, L. J. Foged, M. Sierra-Castañer, "Antenna" Measurement Intercomparison Campaigns in the framework of the European Association of Antennas and Propagation," International Symposium on Antennas and Propagation, ISAP, Nanjing, China, October 2013

19. J.E. Hansen, "Definition, Design, Manufacture, Test and Use of a $12 \mathrm{GHz}$ Validation Standard Antenna, Executive Summary," Technical University of Denmark, Lyngby, Denmark, 1997, Tech. Report R672.

20. L. J. Foged, A. Giacomini, L. Duchesne, E. Leroux , L. Sassi,, J. Mollet, "Advanced modelling and measurements of wideband horn antennas," ANTEM Saint-Malo, June 2005

21. B. N. Taylor, C. E. Kuyatt. NIST Technical Note 1297, "Guidelines for Evaluating and Expressing the Uncertainty of NIST Measurement Results," National Institute of Standards and Technology, UnitedStates Department of Commerce Technology Administration, 1994 Edition.

22. C.F. Stubenrauch; A. Newell, et al "International intercomparison of horn gain at X-band," IEEE Transactions on Antennas and Propagation,Vol.44, Issue: 10, Oct. 1996, Pages: 1367 - 1374 .

23. D. G. Gentle, A. Beardmore, J. Achkar, J. Park, K. MacReynolds, J.P.M. de Vreede, "National Physical Laboratory (NPL) REPORT CETM:Measurement Techniques and Results of an Intercomparison of Horn Antenna Gain in IEC-R320 at Frequencies of 26.5, 33.0 and 40.0GHz," pp. 25-49, September 2003.

24. J. Guerrieri, J. Coder, M. Francis, J. Gordon, D. Novotny and R. Wittmann , "International Comparison of Ku-band - Standard Gain Horn Characterization," National Institute of Standards and Technology.

25. J. Guerrieri, M. Francis and R. Wittmann, "Consensus Value Methods to Compile On-Axis Gain Measurement Results," National Institute of Standards and Technology.

26. R. Kacker, R. Datla and A. Parr,"Combined result and associated uncertainty from interlaboratory evaluations based on the ISO Guide," National Institute of Standards and Technology, 2002. 